\title{
Title
}

\section{'It's small steps, but that leads to bigger changes': evaluation of a nurture group intervention}

\begin{abstract}
This article presents the results of a small-scale research project that aimed to evaluate the effectiveness of a part-time nurture group recently established in one primary school. Qualitative interviews were used to gather staff, pupil and parental perceptions about the nurture group. These focused on what difference the nurture group was making to the pupils concerned but also on views about what factors contributed to noted changes. All stakeholder groups identified areas of development for nurture group pupils. These included improved social skills, growth in personal confidence, greater engagement with academic tasks, and fewer incidences of undesirable behaviour. The evidence gathered so far suggests that the nurture group offered an effective way of supporting the social, emotional and behavioural skills of a group of 'at-risk' pupils. A range of factors thought to be important in achieving these outcomes are highlighted. These align broadly with the theoretical underpinnings of nurture groups.
\end{abstract}

\section{Keywords}

Nurture groups; supporting vulnerable children

\section{Author details:}

Kerry Vincent

Institute of Education

Clifton Campus

Nottingham Trent University

Nottingham

NG11 8NS

01158483497

kerry.vincent@ntu.ac.uk 


\section{'It's small steps, but that leads to bigger changes': evaluation of a nurture group intervention}

\section{Policy context}

Successive governments in the UK have introduced policies that make it clear that schools should now support children's emotional well-being as part of the drive to improve academic standards. Initiatives such as Social and Emotional Aspects of Learning (DfE 2005), the Targeted Mental Health in Schools project (DCSF 2008) and Mental Health and Behaviour in Schools (DfE 2016) each emphasise the importance of providing a range of support for 'vulnerable' pupils. Some documents specifically highlight nurture groups, or strategies typically employed within nurture groups, as useful in this area (see Ofsted 2013; DfE 2016). Additionally, the Revised Special Educational Needs and Disabilities Code of Practice (DfE 2015), which replaced the term 'behaviour' with social, emotional and mental health (SEMH) as one of the four main categories of special educational need, endorses those who argue for a stronger focus on developing children's emotional literacy and well-being (see Faupel 2003; Weare 2011).

Additional funding in the form of the Pupil Premium Grant (PPG), introduced across England in 2011 to raise the attainment of disadvantaged pupils and close the gap between them and their peers (DfE 2014), provides schools with the opportunity to implement a range of strategies for supporting vulnerable pupils, both within and in addition to mainstream provision. Each school must publish on its website how the PPG is spent and is expected to provide 'evidence of impact'. This implies the need for some form of evaluative research. The project reported here involved collating and analysing a range of data which would provide 'evidence of impact' of a part-time nurture group that was being piloted in one primary school. It arose from a university initiative to establish collaborative research partnerships with schools and contributed to the school's own self-evaluation processes.

\section{Nurture groups}

Nurture groups are a school-based intervention that have been used in schools across the UK for more than 40 years. They have gained widespread acceptance as an effective strategy for supporting children, particularly those identified as 'vulnerable' or having social, emotional, behavioural or learning needs that are not easily met with the mainstream class (Boxall 2002; Kourmoulaki 2013). Developed by Marjorie Boxall, an educational psychologist working in 
London in the 1960s and 1970s, nurture principles are drawn from research on early infant attachment (Bowlby 1969) and Maslow's hierarchy of needs (Maslow 1970). According to nurture group theory, children who display developmentally inappropriate behaviour are viewed as having missed the early nurturing experiences that enable them to function successfully at school (Boxall 2002). Nurture groups are seen as a way of making up for this and thereby enabling children to engage with the everyday demands of school and to become fully participating members of their mainstream classes.

Nurture groups share a common set of characteristics which differentiate them from mainstream learning. The staff to pupil ratio is low with most nurture groups catering for between 8 and 12 children and staffed by two adults. The day is highly routinized with a set structure that includes periods of academic focus, social activities, free play and a shared dining experience. Staff offer support and care in consistent ways and model positive social interactions (NGN 2016; Cooper and Whitebread 2007). These characteristics are thought to create predictability and therefore to offer comfort and security. Each child has development targets according to individual need which are identified by psychometric assessment usually the Boxall Profile (Bennathan and Boxall 1998).

Most nurture rooms are equipped with a soft seating area, books and games corner, role-play materials, a dining table and food preparation facilities. Children register with their class each day and join their mainstream peers for part of the week. In the classic nurture model, children attend the nurture group four-and-a-half days a week but there are also part-time variations (see Binnie and Allen, 2008; Scott and Lee, 2009). Children typically spend between two and four terms in the nurture group before a phased re-integration to their mainstream classes. They have been used mainly in primary schools, particularly with younger children, but they have also been adapted for used at secondary level (see Cooke et al. 2008; Scott and Lee 2009).

The growing body of research on nurture groups has demonstrated their potential for supporting children perceived as vulnerable or 'at risk'. Much of the published research on nurture groups has focused on evaluating their effectiveness, particularly in relation to supporting the social, emotional or behaviour development of children. Findings from quantitative, mixed-method and qualitative studies all suggest positive outcomes across these dimensions (Cooper et al. 2001; Cooper and Whitebread 2007; Reynolds 2009; Scott and Lee 
2009; Shaver and McClatchey 2013). The reviews undertaken by the Nurture Group Network (2010) and more recently, Hughes and Schlosser (2014) and Bennett (2015), conclude that nurture group membership improves self-esteem, self-confidence, impulse control, communication and social skills for most children (see also Binnie and Allen 2008; Griffiths 2014; Kourmalaki 2013). There is also tentative evidence that nurture groups contribute to academic gains for some children (Reynolds et al. 2009; Scott and Lee 2009; Seth-Smith et al. 2009).

It is perhaps not surprising then that nurture groups have continued to flourish as an early intervention strategy. The Nurture Group Network (2016) is aware of over 2100 groups currently in operation across the UK, with others in Australia, New Zealand, Canada and Malta. On-going research is therefore important to deepen understandings about this widely used strategy and to ensure that perspectives from all stakeholder groups is available. Currently, the views of children and their parents are not prominent (Griffiths et al. 2014; Shaver and McClatchey 2013) although Cooper et al. (2001) and Pyle and Rae (2015) offer valuable contributions in this area. Illustrations of how increases in psychometric scores (typically the Boxall Profile), play out in the day-to-day lives of particular pupils is rare, and information on the specific skills that nurture group staff use is also scarce (Kourmoulaki 2013). Bennett's (2015) review highlights how little is yet understood about the key ingredients to success and she suggests that qualitative case studies would help shed light on such matters. Additionally, calls have been made for more school-initiated evaluations that are integral to a school's own self-evaluation processes rather than externally commissioned and controlled research (NGN 2010). The research reported in this article aims to contribute to these areas. It presents some of the outcomes of a small-scale research project undertaken in one school. The project aimed to evaluate the impact of a part-time nurture group on children's social, emotional and behavioural development and to identify the features of the intervention that supported observed changes. This would enable the school to make more informed decisions about how it spent some of its PPG, and in the case of positive outcomes, justify the expenditure and provide the required 'evidence of impact'.

\section{The school}

Greenvale Primary School serves around 400 pupils and is located in a socially deprived area in the English Midlands. The school was particularly concerned about a number of pupils who had difficulties coping with a normal school day. Curricular engagement amongst these pupils 
was low, some of them experienced social isolation, and some displayed behaviour that was disruptive to their own learning as well as that of other pupils. Several had been permanently excluded from other schools. The children were perceived to have unmet social, emotional or behavioural needs and the decision was taken to pilot a nurture group (the Beehive) at Key Stage 2 (7-11 year olds).

In line with nurture group principles, the Beehive aimed to provide a short-term, focused intervention that addressed barriers to learning perceived to arise from pupils' social, emotional or behavioural difficulties. Children attended three consecutive afternoons a week, taking part in a range of activities aimed at developing the pro-social and communication skills that would enable them to operate successfully back in their mainstream classes. The daily routine included: circle time, key academic skills, emotional literacy activities, structured games, free play, a shared 'snack' around the dining table and concluded with a shared story. All children registered with their mainstream class in the morning and returned there for the final 15 minutes of the school day. Pupils accessed the Beehive through a formalised referral and assessment process that involved the class teacher, members of the senior management team, Beehive staff and the children's parents. Initial goals that targeted one or more aspects of emotional literacy were identified with the aid of a standardised assessment tool (see Faupel, 2003).

\section{Research methods}

A range of data was gathered to support the evaluation. An emotional literacy assessment (Faupel 2003), taken at entry and towards the end of children's nurture group experience, provided an overall 'emotional literacy' score and an individual profile of strengths and weaknesses across five commonly accepted dimensions of emotional literacy (self-awareness, self-regulation, motivation, empathy and social skills). These were used to help set initial goals for pupils and to provide an indication of growth across these domains, over time. Staff observations of pupil responses to activities were documented on the daily 'planning and evaluation' sheets and provided a further source of evidence of change over time. Semistructured interviews with key stakeholders (staff, parents and children) were also undertaken. These focused on perceived outcomes of nurture group attendance as well as key factors thought to contribute to observed changes. Data was gathered over two-years (2014/15 and 2015/16) in order to allow evaluation of longer-term outcomes for children and to increase the number of participants that could be interviewed. 
This article draws primarily on key findings from the interviews. They were undertaken by the university researcher whose position as an 'interested outsider' was thought to be more likely to encourage open reflection. BERA (2011) ethical guidelines with regard to informed consent, anonymity, the right to withdraw and storage of data were adhered to in conducting all interviews. The name of the school and nurture group are fictitious. All five teachers who had nurture group children in their class across the two years, and the three staff members that ran the nurture group (one teacher and two teaching assistants), were interviewed.

Parent/carer consent was gained to interview 13 pupils (seven in cohort 1 and six in cohort 2) and three parents also agreed to be interviewed. Parents and staff were interviewed individually while 12 of the 13 children were interviewed in pairs, using a 'walking tour' approach (Clark and Moss 2011). Their assent was sought earlier in the week of the interview, and confirmed immediately before. Interviews took place in the third (final) term of each school year. All but one was audio-recorded and then transcribed and analysed thematically.

\section{Changes identified by participants:}

Participants reported a range of positive changes. These fell into four inter-related categories: better social skills, increased confidence, greater engagement with academic tasks, and fewer incidences of undesirable behaviour. Where direct quotes are used, ' $\mathrm{T}$ ' refers to class teacher, ' $\mathrm{P}$ ' to pupil and ' $\mathrm{NG}$ ' to nurture group staff.

\section{Social skills:}

Being able to play and interact positively with other children requires a complex range of skills: the ability to listen to others and to communicate one's own thoughts and feelings, the ability to compromise, share and take turns, and the ability to express empathy (Smith 1998). Most of the children had not yet acquired these skills when they entered the Beehive but progress in this area was identified by all participant groups as an important outcome. Beehive staff, for example, described children as being better at listening and speaking, and more willing to share and take turns. One staff member implied an unexpected level of improvement given the children's starting points, in her description of 'snack time'.

You wouldn't believe the change ... the actual talk at the table, not talking over each other, using the cutlery right, sharing, waiting their turn. (NG1) 
Class teachers also observed improvements in a range of social skills. They made comments relating to specific pupils such as, 'he's better at listening and letting others speak' (T4) or 'he will now share toys, and work with another child, like for a short period ... and turntaking, that's really improved' (T5). Parental reports indicated that in the home setting, children were interacting with siblings in more constructive ways and all three parents described their children as better listeners. There was agreement from the children themselves. In response to a question about what he had learned since coming to the Beehive, one child replied, 'I've learned to listen to everybody, and making new friends' (P10).

Some children's games produce winners and losers. Being able to manage both positions is therefore important for successful participation in such activities. Most of the children in the Beehive initially had difficulty with losing a game and demonstrated this with emotional or physical outbursts. However, this changed over time. In-line with emotional literacy commentary (Morris and Casey 2006; Education Scotland 2016), Beehive staff attributed this to the child having developed a more resilient self-concept. As one staff member noted:

And when they're losing, lots of them hate that losing part. Now some of them will lose ... 'that's OK, I've enjoyed it'. Their self-esteem is still OK. (NG1)

Further evidence of children learning to lose gracefully was found in the daily planning and evaluation sheets. Notes for one pupil, taken over several weeks, revealed that when he started in the Beehive he did not know about board games. He had never played one before and was not familiar with the accepted practices of turn-taking and moving forward according to the roll of a dice. Early on, it was noted that he, 'didn't roll the correct number in board game so threw things across the table'. However, several weeks later he was, 'playing better-played fairly and did not sulk or get cross'.

Pupil accounts corroborated these findings. During the walking tour pupils showed me the stickers they received for 'being good'. Their understandings of 'being good' included behaviours such as:

Like, I'd be playing nicely with others (P8)

Or like, if I was playing a game, and if I'm losing, I wouldn't stamp off (P9) 
Class teachers also noticed this change, making statements such as:

Winning used to be really important, but now, he's OK not winning (T1).

Growing competence in a range of social skills, such as those illustrated above, will help the children establish stable, reciprocal relationships with peers, staff and family members. In turn, this is likely to pay dividends in relation to their self-esteem and sense of belonging. These have been recognised as important psychological needs, that when met, increase the likelihood of pro-social behaviour, enjoyment of school and academic motivation (DfE 2016; Faupel 2003; Osterman 2000). The children's developing social skills may therefore have contributed to some of the other changes identified.

\section{Increased confidence}

Greater personal confidence was another change highlighted by interviewees. This was based on observations of children engaging in activities that had formerly been avoided. One child, for example, was initially unwilling to participate in a group game, despite considerable encouragement from Beehive staff. Support was offered over several weeks until the child was able to participate independently. Interestingly, the excerpt below indicates that the children had also begun to support each other, an outcome highlighted in Kourmoulaki's (2013) research of nurture groups in a secondary school. This required empathy - in this case, the ability to recognise the anxiety that this activity induced for P5.

[P5's] confidence is massive compared to what it was. We've got this board game ... where they move around the alphabet based on animal names. When we played it this week he just did it, without us have to help him. He might still hesitate a bit ... but he looks like he's enjoying it. And the others are, 'well done [P5], you did it'. They could recognise that he didn't enjoy it before. (NG1)

Class teachers also described children as more confident. This was based on children persevering with academic work rather than giving up quickly, being more willing to seek assistance if needed, and speaking out more in class. One teacher, for example, stated:

Last week she came up to the front of the class to show her example. She would never have done that six months ago (T5). 
Increased confidence appeared to go hand-in-hand with increased self-esteem, as exemplified by being able to accept a compliment. This requires believing oneself to be both competent and worthy of recognition (Morris and Casey 2006). The teacher gave several examples of a different pupil being able to accept praise for something well done. As she noted, 'In September, she couldn't even handle 'well done', (T5).

Parents too, perceived their children as more confident since attending the Beehive. They described their children as more independent and more likely to persevere with tasks at home. One parent described his son as more willing to initiate social contact with other children, while another described her son as taking greater pride in his appearance and personal hygiene. They attributed these changes to greater self-confidence and improved self-esteem. Maslow (1970) describes self-esteem and confidence as important aspects of 'esteem', which he argues is a basic human need. Time in the Beehive seemed to go some way to meeting this need.

\section{Fewer incidents of undesirable behaviour}

Some of the children in the Beehive had a history of engaging in behaviours that disrupted their own learning as well as that of others. Behavioural concerns included non-compliance with teacher instructions, physical and verbal aggression towards staff and other pupils, and frequent altercations with other pupils. Participants highlighted a reduction in the frequency, duration or intensity of these behaviours. The noted changes reflect improvements in selfregulation, but changes in self-awareness and empathy were also evident.

All three adult stakeholder groups suggested that the children now remained calmer when stressed, or calmed down more quickly after becoming emotionally upset. This appeared to go hand-in-hand with their ability to recognise, manage and communicate feelings in socially approved ways. For one pupil, this was demonstrated by fewer angry (sometimes violent) outbursts, and fewer incidents of him running off when he did become upset.

When he first came into the classroom, anything that upset him, and it might be the most miniscule thing, he'd push back his chair and run out of the classroom. And that gradually became less and less. (T2) 
For another pupil, greater self-regulation was indicated by fewer incidents of hurting other children. Teachers, and one parent commented on fewer playground incidents. The changes illustrated in the excerpt below indicate greater levels of self-awareness and self-regulation than earlier in the year. It also illustrates a pupil's ability to communicate feelings in more socially approved ways.

He came in from the dinner break earlier this week and said, 'Pupil x has made me angry'. Before, he would have just hit him. (T5)

School behaviour records reflected these changes. Four of the five pupils who had a record of 'serious incidents', reduced these over their time in the nurture group, in three cases, to zero per term.

Parents perceived their children as more emotionally aware and more communicative about their emotions at home. Their comments support the teachers' perceptions of social, emotional and behavioural development. The account below suggests that greater empathy underpins the better sibling relationship.

And he understands his feelings better ... and also other people's [feelings] ... like he'll look after [younger sister] more now ... and be more patient, instead of belting her ... and he'll apologise if he's upset her (P2).

Participants also highlighted children's greater willingness to take responsibility for their own behaviour, as demonstrated by recognising when they have behaved inappropriately, and making amends, for example, through an apology. Overall, these observed behavioural changes suggest greater self-awareness, empathy and self-regulation.

\section{Engagement with academic tasks}

The play-based and emotional literacy-focused programme offered in the Beehive was founded on the assumption that supporting children's social and emotional development will, in the long-term, pay dividends in relation to academic achievement. The research evidence for this limited, partly because it is difficult to prove empirically, but also because doing so would require longer-term studies than those that have typically been undertaken on nurture 
groups. There is some evidence, however, that low levels of emotional literacy correlate with poor behaviour and underachievement in school (Faupel 2003).

Although actual levels of academic achievement were not investigated as part of this research, Beehive staff highlighted improved engagement with academic tasks as an observed outcome. Speaking in general terms about Beehive pupils, one staff member noted:

We used to get, 'oh, no, do we have to do key skills' or 'oh, no, why do I got to do work' ... but now, when its key skills time, they just go and do it. It's like, 'OK, it's key skills, what are we doing today?' (NG1)

Greater academic focus was also evident in mainstream classes. Poor academic engagement had been one of the factors considered when selecting pupils for the Beehive and all five teachers perceived the children as more academically engaged than earlier in the year. A teacher who had four Beehive pupils in her class suggested:

They're better at engaging, like at the beginning of the lesson ... listening, questioning ... just like the other children. They'll have the odd moment of distraction, but really not that different from the others now. (T1)

For some pupils, the perceived improvement was more modest, as indicated by teacher statements that a pupil would now 'make a start' (T2) or 'work for short periods independently' (T4). However, seen against the backdrop of a history of disengagement, seemingly small improvements such as these could be considered an important step in the right direction. Speaking about a pupil in her class, one teacher stated:

Last year his work output was basically nil because of his behaviour, particularly when he was kicking off with [pupil x]. But now, he'll get his book out and make a start ... that's an improvement. (T2)

Another teacher described one of her Beehive pupils as academically able but underachieving. She explained that the pupil's ability to concentrate and persevere with tasks was noticeably better than earlier in the year and that as a result, she completed more work. She added, 'If she hasn't finished something, she'll take it to the Beehive to finish in the afternoon'. This high 
degree of motivation towards academic work had been absent earlier in the year. While a noticeable impact on children's academic achievement levels may not yet be evident, it seems reasonable to expect this as a longer-term outcome.

\section{The 'how' and the 'why'}

The school was also interested in understanding more about how and why the Beehive worked for particular pupils and what might be learned from nurture group practices that might be applicable more widely throughout the school. Staff views on how some of the observed outcomes had been achieved centred around six key components. Some of these related to specific content of the programme offered, or to specific strategies employed by staff, while others were more general strategies that might be applied more widely. Links can also be seen to the theoretical understandings upon which nurture groups are based.

First, staff thought that embedding emotional literacy into all aspects of what they did was integral to what the children had achieved. They spoke about the lack of awareness and understanding of feelings that children had on arrival in the Beehive. They noted:

We do work on feelings ALL the time. Every day we do something to do with feelings. Most of them, at the start ... they usually know happy and they usually know sad, but other than that ... they just don't know. (NG1)

Helping children to recognise, understand and accept a wide range of feelings was viewed as an important precursor to some of the behavioural changes that staff wished to see, and as implied in the statement below, children learned to distinguish between 'feeling' and 'behaving'.

We've covered a wide range [of feelings]. And some of the children have experienced loss. We let them know that it's OK to have these feelings ... but it's how we handle them and how we respond [that's important]. (NG2)

Expanding the repertoire of responses available to pupils was therefore an important aspect of staff member's work with children. One pupil, for example, described learning to take himself to a quiet place to help him calm down, and to, 'pull the blanket over my face or count to ten' $(P 7)$. Another pupil recounted choosing to walk away from a situation that previously would 
have entailed a physical altercation. It seems likely that greater awareness of their own and others' feelings, coupled with an expanded repertoire of behavioural responses, helped the children to behave in more socially acceptable ways. Developing children's emotional literacy was seen as integral to this.

The adult modelling, alongside constant repetition and encouragement were seen as important contributors to improvements in children's behaviour, particularly in how they listened and spoke to one another. When asked about how she thought some of the noted changes were achieved, one staff member stated:

Just through the modelling ... and the constant repetition ... like you would for a toddler. And then when they do need help ... it's 'miss I can't spread' ... so it's 'yes you can' and you show again and then 'now you have a go'. And we're just constantly going over and modelling for them until they get it. (NG1)

The repetitive modelling went hand-in-hand with recognising, accepting and building on children's starting points. This often meant 'going back to basics' and spending time learning skills that many children of their age had already acquired.

For a lot of them, we're going back to basics ... even just listening. And sharing, that's a big one. It's difficult for them. We do sometimes have snatching, and we'll talk about that. It's us modelling behaviour all the time ... and talking things through. (NG2)

These views reflect Boxall's (2002) emphasis on providing consistent modelling and the importance of identifying and working at children's current levels of competency which, she argues, helps reduce frustration and build self-esteem. These environmental characteristics may also help explain the noted increase in children's confidence. Some children were initially reluctant to attempt new activities. This could be attributed partially to the anxiety produced when faced with a new activity as well as anxiety about losing face in front of classmates if expectations were not met. As Boxall (2002) notes, children with fragile selfconcepts are less resilient when faced with new or demanding situations. Participating in a range of activities in a supportive environment is one way of supporting the development of confidence and self-esteem. 
The quality of the relationship between staff and pupils was a fourth theme to emerge. Staff accounts allude indirectly to the concepts of care, acceptance and respect that recurs in much work with 'troubled' or 'troublesome' pupils (see Pomeroy 2000; Vincent et al. 2007). This was conveyed, for example, through staff responses to children being consistent and predictable and by staff listening to what children had to say.

And we never shout, we never get cross. We talk to them. So many of them don't get talked to ... they get shouted at. We sit and talk ... and we listen ... give them a chance to actually say. (NG1)

This also aligns with the theoretical underpinnings of nurture groups. Boxall (2002) hypothesises that the predictability of the staff responses, alongside the consistent routines, provide comfort and security and help build trust. In the Beehive, these aspects were further reinforced through the attention and physical affection that children received. As illustrated below, staff found that the 'cosiness' of the shared story at the end of the day, and also the consistency of this routine, were an important part of the day for the children.

And there's the affection ... the cuddles. Some of them when they first came, they didn't know about sitting and having a story, sitting nice and cosy ... or a cuddle ... and now they do want that ... we've found that's a really important part of their day (NG1).

The importance of this part of the room and the activities that take place there, was supported by the fact that all of the children chose to show me the 'feelings' and 'story-time' corner during the classroom tour. Their accounts highlighted aspects of their nurture group experience that differ from what is available in their mainstream classrooms. As one child recounted:

Well at story time, we sit here. You can get a blanket and a pillow and you can listen to the story and lie down ... with the teddy. (P10)

The fifth component that staff considered to be integral to observed outcomes was that goalsetting was individually tailored for each child. Worthy of note is that it may be the 'how' and 
not only the 'what' that increased the impact of this part of the programme. Each child had an individual goal which was established via a joint process between the child and a staff member and based around the emotional literacy assessment results. This is likely to have promoted a sense of personal ownership over the goal, but to also serve as a tangible demonstration to the children that their views were important and that they would be listened to.

As one staff member noted:

They're all in there for all different reasons so we have to make sure we're focusing on what's important for them. That's why they have the individual goals. (NG2)

The final theme to emerge from staff accounts was that change may take a long time. In their words, 'it's small steps, but that leads on to bigger changes' (NG2) and it takes, 'patience ... a lot of patience' (NG1). One staff member recounted the successful reintegration of a girl whose younger brother had recently started in Treehouse. She reported that the younger brother's current behaviour reminded them of how the older sibling used to be. She highlighted both the egocentric behaviour that most children of that age have moved on from, and thus why they were seen as good candidates for a nurture group, but also that change takes time.

And now we've got her brother ... so with him it's back to square one. He talks over everyone all the time, it's all 'me, me, me' ... and when we think back to his sister in September, that was her. We just forget because the change is so gradual. (NG1)

Worthy of noted is that the school's commitment to the children extended beyond their time in the Beehive. Reintegration to their mainstream classes was achieved through a carefully planned and supported transition over time. One pupil, for example, had difficulty having his dinner in a noisy, densely populated hall and so ate his meal in the Beehive before joining the other pupils in the playground. Another pupil received some in-class support as part of his reintegration plan, while another was receiving a weekly play therapy session. These supports represent on-going forms of nurturing. They appear to have been effective in supporting pupils' reintegration to their mainstream classes as well as participation in the wider life of the school. 
Teachers and parents also contributed views on the factors they thought helped achieve positive outcomes. All five teachers, as well as the three parents, pointed to the small group size and the nurturing that this facilitates. The teachers felt unable to offer the same degree of individual attention within their larger classes as the children received in the small-group setting. Two teachers also highlighted teamwork as important. They saw themselves and Beehive staff as working together towards a common goal. This was made obvious to the children through regular communication and through class teachers visiting the Beehive and vice versa. Children's successes, whether in the mainstream or in the Beehive, were shared across settings. Additionally, these class teachers knew what children's individual goals were and encouraged children to talk to them about what they had been doing in the Beehive.

\section{Discussion and conclusion}

The small-scale nature of this study, as well as the qualitative nature of the data, limit its generalisability. However, the consistency of the findings between the different stakeholder groups, and the illustrative examples of change that were provided, contribute to the growing evidence of the efficacy of nurture groups in supporting the social, emotional and behavioural development of the children who attend them. Moreover, the process was a useful way of enabling the school to provide the required 'evidence of impact' and thus to make a more informed choice about how it spent some of its PPG. It also adds to understandings about how and why nurture groups are a useful intervention for some children.

In-line with other qualitative studies, the data suggest that the Beehive contributed to a range of positive social, emotional and behavioural outcomes for the children. These included better social skills, growth in personal confidence, greater engagement with academic tasks, and fewer incidences of undesirable behaviour. The examples used to illustrate positive outcomes reflect changes in observable behaviour and although the degree of improvement varied from pupil to pupil, there was a high degree of consistency in perceptions about these outcomes across all stakeholder groups.

Nurture group provision tends to target younger children, and indeed, research suggests that outcomes tend to be better and more rapid with younger children (Sanders, 2007; Scott and Lee, 2009). The school in this study chose to pilot its nurture group at Key Stage 2, in part, because an intervention was needed for the particular group of individuals that formed the 
first cohort. The findings of the study support other research that shows that nurture groups can also be effective with older children (ibid) and when offered on a part-time basis (Binnie and Allen 2008; Kourmoulaki 2013). Given current constraints on school budgets, the additional resourcing implications of staffing a classic nurture group model (4 1/2 days per week), may be more difficult to justify. Evidence for efficacy for part-time nurture provision is therefore important.

Positive outcomes were attributed to a range of factors, many of which align closely with the theoretical underpinnings of nurture groups. The specific focus of the programme, in particular the strong emphasis on developing children's emotional literacy, was seen as key to the observed changes. This is one element that could be incorporated more widely into the school's mainstream teaching practices. The consistency of the daily routines, the repetitive adult role modelling of skills, and the predictability of adult responses to children, were also seen as important. These could equally receive greater attention within mainstream teaching practices. Additionally, staff developed a close and supportive relationship with the children and they identified and worked at children's current levels of competence thus enabling them to experience success and grow in confidence. This was aided by listening to children, valuing their contributions, and tailoring what was offered so that it addressed individual needs. These aspects were made possible by the low adult-to-child ratio that characterise nurture groups. This makes them harder to incorporate into daily mainstream teaching without significant changes to the systems and structures that constrain much of what goes on in schools.

Finally, staff expectations about pupils was high but realistic. They believed that all of the children could, and would, make progress across a range of social, emotional and behavioural dimensions. However, they were realistic and accepted that there were no quick fixes and that for most of the children, the desired changes would take time. This required a long-term commitment to pupils. For some of the children, this was reflected in access to various forms of nurturing that extended beyond their time in the Beehive. There was also close communication between Beehive staff and children's class teachers. This meant that the nurture group did not stand in isolation. The importance of both of these characteristics has been highlight in other research (Cooper and Tiknaz, 2007) and could usefully be applied to any intervention aimed at supporting vulnerable pupils. 
The evidence that has been gathered over the last 40 years leaves little doubt about the value of nurture groups in supporting vulnerable children. However, as highlighted in Bennett's (2015) systematic review, there is still much to be learned about the exact mechanisms and variables that impact on their effectiveness. This study has drawn attention to just a few. The continuing and widespread use of nurture groups mean that deepening understandings about how different pupil and group-related factors, organisational issues, and school-related factors impact on outcomes, will be important for maximising the benefits for children who access nurture group interventions. 


\section{References}

Bennathan, M. and M. Boxall. 1998. The Boxhall Profile: Handbook for Teachers. London: Nurture Group Network.

Bennett, H. 2015. "Results of the Systematic Review on Nurture Groups'

Effectiveness." International Journal of Nurture in Education 1 (1): 3-8.

BERA (British Educational Research Association). 2011. Ethical Guidelines for Educational

Research. http://www.bera.ac.uk.

Binnie, L., and K. Allen. 2008. "Whole school support for vulnerable children: the evaluation of a part-time nurture group." Emotional and Behavioural Difficulties, 13 (3): 201-216.

Bird, W., E. Burton, A. Maryon-Davis, M. Murphy, S. Stewart-Brown, K. Weare, K. and P.

Wilson. 2011. Thinking Ahead. Why we Need to Improve Children's Mental Health and Wellbeing. London: Faculty of Public Health.

Bolby, J. 1969 Attachment and Loss. Volume 1: Attachment. London: Hogarth Press.

Boxhall, M. 2002. Nurture Groups in School: principles and practices. London: Paul Chapman.

Clark, A., and P. Moss. 2011. Listening to Young Children: The Mosaic Approach. London: National Children's Bureau.

Cooke, C., J. Yeomans, and J. Parkes. 2008. “The Oasis: Nurture Group Provision for Key Stage 3 Pupils", Emotional and Behavioural Difficulties 13 (4): 291-303.

Cooper, P., R. Arnold, and E. Boyd. 2001. "The Effectiveness of Nurture Groups: Preliminary Research Findings”, British Journal of Special Education, 28 (4): 160-166.

Cooper, P., and Y. Tiknaz. 2007. Nurture Groups in School and at Home. Connecting with Children with Social, Emotional and Behavioural Difficulties. London: Jessica Kingsley. Cooper, P., and D. Whitebread. 2007. "The Effectiveness of Nurture Groups on Student Progress: Evidence from a National Research Study”, Emotional and Behavioural Difficulties, 12 (3), 171-190.

DCSF (Department for Children, Schools and Families). 2008. Targeted Mental Health in Schools Project. Nottingham: DCSF Publications.

DfE (Department for Education). 2016. Mental Health and Behaviour in Schools.

http://www.gov.uk/government/uploads/system/uploads/attachment_data/file/508847/Mental Health_and_Behaviour_-_advice_for_Schools_160316.pdf.

DfE (Department for Education). 2015. Revised Special Educational Needs and Disabilities Code of Practice. London: DfE. 
DfE (Department for Education). 2014. The Pupil Premium: Funding and Accountability for Schools. http://www.gov.uk/guidance/pupil-premium-information-for-schools-andalternative-provision-settings.

DfES (Department for Education and Skills). 2005. Excellence and Enjoyment: Social and Emotional Aspects of Learning.

http://www.education.gov.uk/publications/eOrderingDownload/DFES0110200MIG2122.pdf.

Education Scotland. 2016. Journey to Excellence. Research Summary-emotional intelligence.

http://www.journeytoexcellence.org.uk/resourcesandcpd/research/summaries/rsemotionalintel ligence.asp.

Faupel, A. ed. 2003. Emotional Literacy: Assessment and Intervention. Ages 7-11. Southampton Psychology Service. London: GL Assessment.

Griffiths, R., R. Stenner, and U. Hicks. 2014. “Hearing the unheard: children's constructions of their Nurture Group experience”, Educational and Child Psychology, 31 (1), 124-136.

Hughes, N. and A. Schlosser, A. 2014. "The Effectiveness of Nurture Groups: a Systematic Review." Emotional and Behavioural Difficulties, 19 (4): 386-409.

Kourmoulaki, A. 2013. "Nurture Groups in a Scottish Secondary School: Purposes, Features, Value and Areas for Development." Emotional and Behavioural Difficulties, 18 (1): 60-76. Maslow, A. 1970. Motivation and Personality. New York: Harper and Row.

Morris, E. J. Casey. 2006. Developing Emotionally Literate Staff. London: Paul Chapman. Nurture Group Network. 2016. http://www.nurturegroups.org.

Nurture Group Network. 2010. Making Our Experience Count. The views of nurture group practitioners throughout the UK. Wigan: Nurture Group Network.

Osterman, K. 2000. "Students' Need for Belonging in the School Community." Review of Educational Research, 70 (3): 323-367.

Ofsted. 2013. The Pupil Premium. How Schools are Spending the Funding Successfully to Maximise Achievement. Manchester: Ofsted.

Pomeroy, E. 2000. Experiencing Exclusion. Stoke-on-Trent: Trentham.

Pyle, A. and T. Rae, T. 2015. Nurture Groups and Parent-Child Relationships. Exploring Parents' and Children's Perceptions of Nurture Groups and the Ways in Which they Impact upon Parent-Child Relationships The International Journal of Nurture in Education 1 (1): 9-14. Reynolds, S., T. MacKay, and M. Kearney. 2009. "Nurture Groups: a Large-Scale, Controlled Study of Effects on Development and Academic Attainment." British Journal of Special Education, 36 (4): 204-212. 
Scott, K. and A. Lee. 2009. "Beyond the 'Classic' Nurture Group Model: an Evaluation of PartTime and Cross-Age Nurture Groups in a Scottish Local Authority." Support for Learning, 24 (1): 5-10.

Sanders, T. 2007 "Helping Children Thrive at School: the Effectiveness of Nurture Groups." Educational Psychology in Practice, 23 (1): 45-61.

Seth-Smith, F., N. Levi, R. Pratt, P. Fonagy, and D. Jaffey, D. 2010. "Do Nurture Groups Improve the Social, Emotional and Behavioural Functioning of at Risk Children?" Educational and Child Psychology, 27 (1): 21-34.

Shaver, I. and K. McClatchey. 2013. "Assessing the Effectiveness of Nurture Groups in Northern Scotland.” Support for Learning, 28 (3): 97-102.

Smith, A. (1998) Understanding Children's Development. Wellington, NZ: Bridget Williams Books.

Vincent, K., B. Harris, P. Thomson, and R. Toalster. 2007. "Schools Collaborating for Collective Gain”. Emotional and Behavioural Difficulties, 12 (4): 283-297. 